\title{
In vitro sensitivity testing of human renal cell carcinoma with cytostatic agents and interferon Alpha-2a
}

\author{
W. de Riese, E. Allhoff, C. G. Stief, G. Lenis, R. Schlick, S. Liedke, P. Anton, and U. Jonas \\ Department of Urology, Hannover Medical School, Hannover, FRG
}

Accepted: March 1, 1990

Summary. Samples of 38 human renal cell carcinomas (RCC) were subjected to routine histopathological examination but also to in vitro sensitivity testing with mitomycin $\mathrm{C}$, vinblastine and interferon Alpha-2a at various concentrations corresponding to serum titers recommended to be effective in vivo, employing a monolayer assay. Extending earlier in vitro studies, both tumor cell kill rates (TCKR) and proliferation rates (PR) were assessed. Following in vitro preparation the tumor cell cultures were simultaneously exposed to the anticancer drugs listed above. The proliferation rates were determined immunocytochemically using the monoclonal antibody Ki-67. Nine $(23.7 \%)$ of the tumors investigated revealed temporary and limited response with respect to either TCKR or PR. Improvement of this percentage could only be obtained by increasing drug concentration to titers with toxicity intolerable for in vivo administration. The in vivo data presented correspond to clinical temporary and limited remissions in patients with metastatic RCC ranging up to $25 \%$.

Key words: $\mathrm{RCC}-$ In vitro sensitivity testing

Approximately $30 \%$ of patients have metastases at the time renal cell carcinoma (RCC) is diagnosed [15]. Conventional modern management of advanced solid tumors applies cytotoxic agents. Despite the remarkable advances achieved in other tumors, RCC has remained unmanageable by these agents. Numerous drugs have been administered as single agents predominantly vinblastine nowadays [2, 3]. Hrushesky and Murphy reported a $25 \%$ objective response, superior to any other single agent or combination therapy [14], which was also confirmed by other investigators $[3,13]$. The interferons represent glycoproteins produced by human cells in response to viral infections as well as various other inducers. The antiviral and antineoplastic activity is mediated either by direkt or indirect tumor cytotoxicity via natural killer cell stimulation or both $(10,20,24)$. Complete and partial remission rates ranging from $20 \%-25 \%$ have been report- ed for patients with lung metastases of RCC treated with interferon-alpha, while patients with bone metastases showed nearly no response to this treatment $[2,3,5,6,21]$.

$\mathrm{RCC}$ is a pleomorphic malignoma [17]. To detect the biological behavior of renal tumor cells under treatment we studied 38 different human RCCs in vitro, exposing them to different cytotoxic agents such as mitomycin, vinblastine and interferon-alpha-2a. Cell response under treatment was assessed by determining the tumorcell kill rate (TCKR) and the proliferation rate (PR)

\section{Material and methods}

Tumor tissue of 38 patients with RCC was prepared and analyzed. According to the method recently described [16] the procedure of cell preparation was chosen as follows:

Tumors from previously untreated patients were obtained by conventional tumor nephrectomy, and a macroscopically homogenous area lacking fibrosis, necrosis, or hemorrhage was excised for preparation. Figure 1 exhibits the tumor cell preparation schematically.

One sample of the excised tumor tissue was taken for in vitro cell preparation, another sample for histological examination as a "reference slide." In earlier investigations this procedure has been proved to produce pure tumor cell cultures, employing cytogenetic [16] and immunocytochemical methods [22].

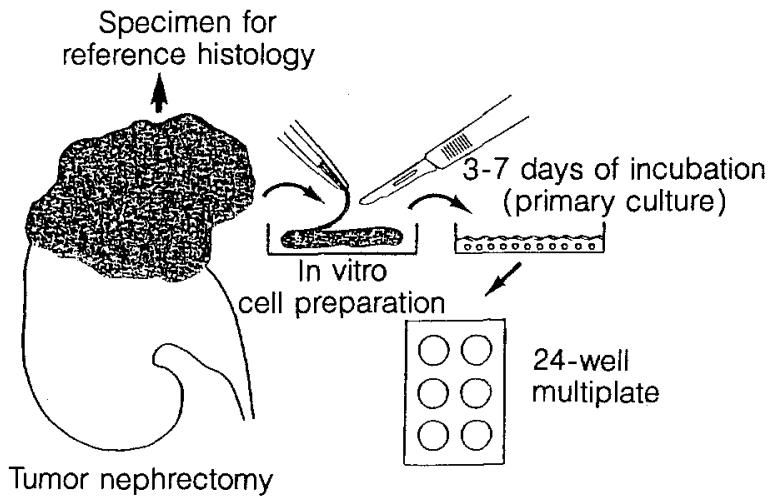

Fig. 1. Preparation of malignant renal cells for in vitro drug sensitivity testing 


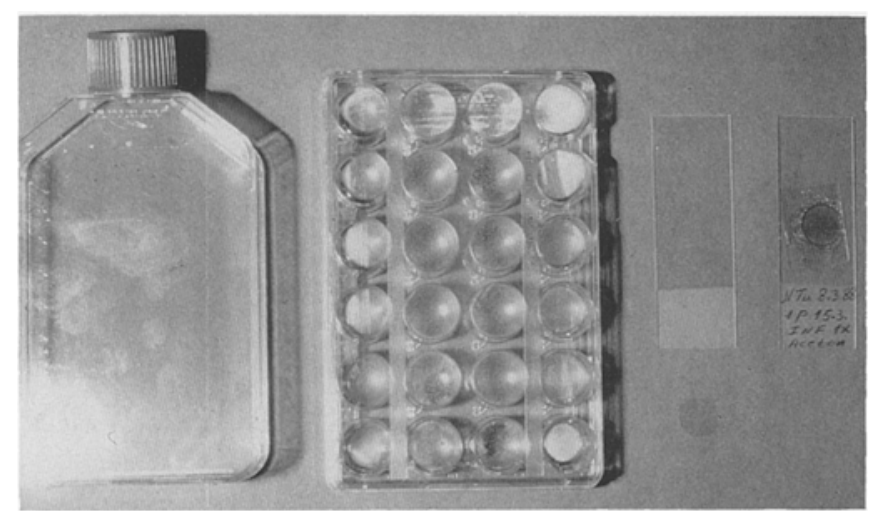

Fig. 2. The $25 \mathrm{~cm}^{3}$ flask for cell culturing, the 24-well multiplate and the "Thermanox" platelets which can be attached to conventional glass slides

Table 1. Drug concentrations used for RCC in vitro sensitivity testing

\begin{tabular}{lc}
\hline Drug & Single concentration $^{\mathrm{a}}$ \\
\hline Mitomycin C & $0.50 \mu \mathrm{g} / \mathrm{ml}$ \\
Vinblastine & $0.15 \mu \mathrm{g} / \mathrm{ml}$ \\
Interferon alpha-2a & $30 \mathrm{U} / \mathrm{ml}$ \\
\hline
\end{tabular}

$\mathrm{RCC}$, renal cell carcinoma

a Based on the recommended therapeutic serum (in vivo) concentrations, the drugs were tested in single, double, five- and tenfold concentrations; Interferon alpha-2a was additionally tested in 20fold concentration

Fast Red

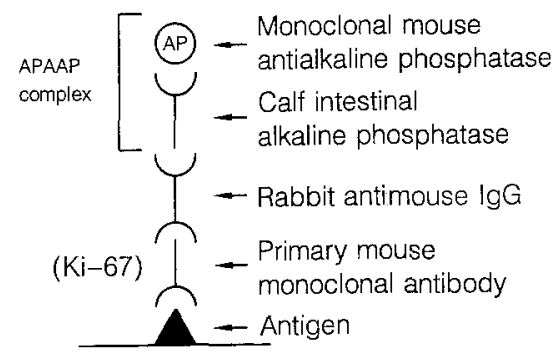

Fig. 3. Immunocytochemical labeling using the monoclonal antibody $\mathrm{Ki}-67$ and the alkaline phosphatase antialkaline phosphatase complex. $A P$, alkaline phosphatase

\section{Preparation of primary cell cultures}

After mechanical and enzymatic treatment the tissue fragments were centrifuged and washed twice in RPMI 1640 medium. Subsequently the tissue clusters were resuspended in a centrifuge tube containing 2-4 ml culture medium (RPMI 1640 supplemented with $15 \%$ fetal calf serum and $1 \%$ penicillin) and dispersed vigorously by means of a Pasteur pipette. The suspension sedimented for $1 \mathrm{~min}$ and the supernatant containing over $90 \%$ of single cells with low viability and cell debris was decanted. The pellet consisting of over $90 \%$ of small cell clusters with approximately $10-15$ cells was resuspended and seeded in culture. The cell clusters were incubated at $37^{\circ} \mathrm{C}$ in a humidified atmosphere containing $5 \% \mathrm{CO}_{2}$ in $25 \mathrm{~cm}^{2}$ Falcon flasks (BIOCHROM, 1000 Berlin, FRG), each flask containing $5 \mathrm{ml}$ of culture medium. The small cell clusters attached to the flasks within
$24 \mathrm{~h}$ and grew out to an almost confluent monolayer, in most cases within 3-7 days after seeding.

\section{Preparation of in vitro slides}

After decanting the medium of the primary cultures, the cells were washed twice with warm $\left(37^{\circ} \mathrm{C}\right)$ trypsin to remove cell debris and remaining blood cells. One part of the cell clusters were transferred to another culture flask for further subculturing processes, the other part was pipetted equally into 24-well multiplates containing $3 \mathrm{ml}$ culture medium without any antibiotics and each well was equipped with one plastic platelet (Thermanox, NUNC, 6200 Wiesbaden, FRG). This efficient technique, developed in Hannover, increases the amount of cells on slides, thus diminishing the loss of material, because cells grow much better on the rougher surface of plastic than on glass (Fig. 2).

In 3-7 days after the first cell passage the untreated cells had grown to a confluent monolayer, which has considered the starting point for evaluation of the treated and untreated cells on the platelets. The cells either were fixed in acetone or chloreform (for immunohistochemical staining [7]) and subsequently attached to conventional glass slides by using a special adhesive (LOCTITE Comp., FRG). Finally staining was performed as described.

\section{Short-term in vitro sensitivity testing}

Within the logarithmic cell growing phase the culture medium of the 24-well multiplates was changed, administering the therapeutic agents (mitomycin, vinblastine, interferon alpha-2a) in different doses. In Table 1 the single drug concentrations transferred from in vivo to in vitro conditions according to Hamburger and Salmon are outlined [11]. Only single drugs, not multiple drugs were administered to the tumor cell suspensions. The drugs were tested in single, two-, five- and tenfold concentrations. In addition interferon alpha$2 \mathrm{a}$ was tested in 20 -fold concentration (equivalent to $100 \times 10^{6} \mathrm{U} /$ $1.75 \mathrm{~m}^{2}$ in vivo). For each tumor two culture wells with no administration of therapeutic agents (control group) and two culture wells per tested drug concentration were used. The platelets were taken for immunocytochemical determination of the PR with the monoclonal antibody Ki-67 [7] (DIANOVA, 2000 Hamburg, FRG). There were 28 platelets per each prepared tumor.

On the average, the platelet surfaces of the control groups were fully covered with tumor cells within $2-4$ days after cell passage. This was considered the starting point for cell counting to obtain the TCKR comparing the number of treated cells with that of untreated cells [23].

Gerdes and coworkers made available the monoclonal antibody $\mathrm{Ki}-67$, which binds to a human nuclear antigen associated with cell proliferation [8]. Cell cycle analysis demonstrated that the nuclear antigen detected by $\mathrm{Ki}-67$ is expressed only in the G1, S, G2, and M phases of proliferating cells regardless of whether a tumor is malignant, but is absent in G0 cells [9]. The Ki-67 assay thereby established an easy, fast, and reproducible method of determining the growth fractions of tumor in situ.

According to Gerdes [7] 200 cells in four different areas of each specimen were counted to measure the proportion of Ki-67-positive cells. The technique for immunocytochemical staining was first described by Gerdes in 1985 [7] and is presented schematically in Fig. 3. The acetone- and cloroform-fixed cells are exposed to the monoclonal antibody diluted in RPMI 1640 medium for approximately 30 min. After washing in tris-buffered solution ( $\mathrm{pH} 7.4-7.6$ ), the cells are incubated with rabbit antimouse IgG followed by exposition to alkaline phosphatase antialkaline phosphatase (APAAP) complex after another washing [4]. Subsequently the slides are stained with "fast red" and counterstained with hemalum [4]. Presence of the specific antigen is indicated by a red instead of blue color reaction after counterstaining. 
Table 2. Histological grading and staging of 38 renal cell carcinomas tested in vitro for drug sensitivity

Histological grading and staging

\section{$n$}

$\begin{array}{lr}\text { G1, pT1-2 } & 8 \\ \text { G1, pT3-4 } & 2 \\ \text { G2, pT1-2 } & 5 \\ \text { G2, pT3-4 } & 12 \\ \text { G3, pT1-2 } & 4 \\ \text { G3, pT3-4 } & 7\end{array}$

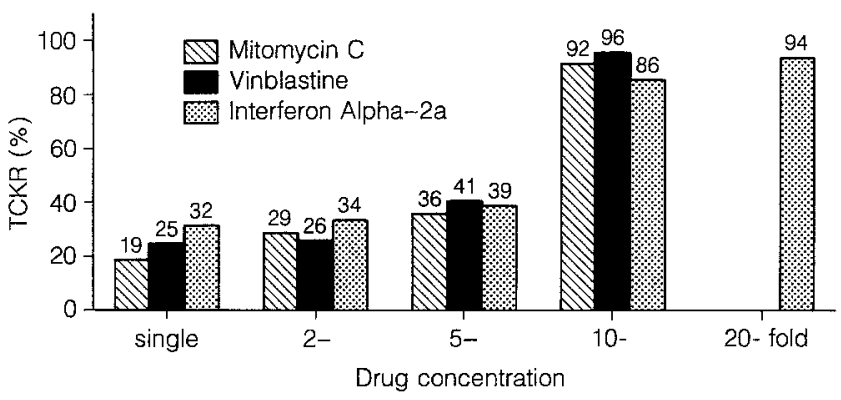

Fig. 4. Average tumor cell kill rates (TCKR) of 38 primary renal cell tumors tested in vitro under exposure to different concentrations of cytostatic agents (mitomycin $\mathrm{C}$, vinblastine) and interferon Alpha$2 \mathrm{a}$

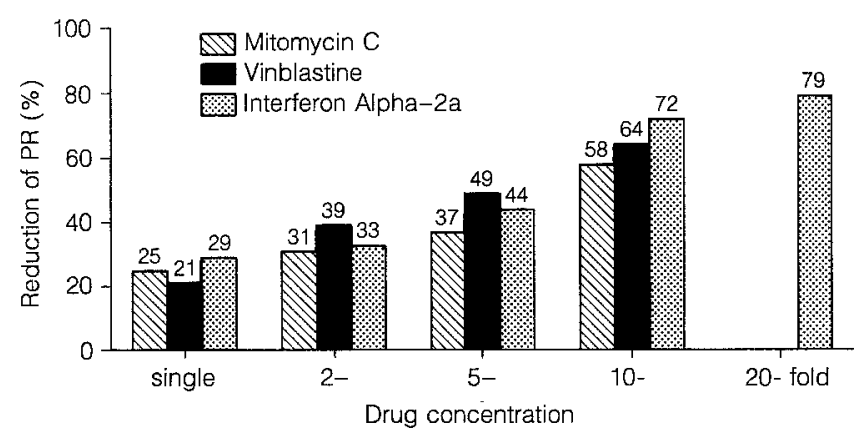

Fig. 5. Average reduction of proliferation rates (PR) of 38 primary renal tumors tested in vitro under exposure to different concentrations of cytostatic agents (mitomycin $\mathrm{C}$, vinblastine) and interferon Alpha-2a

Table 3. Histological grading and staging of 38 renal tumors which were partially sensitive in the in vitro drug testing

\begin{tabular}{llll}
\hline Grading and staging & $n$ & $\begin{array}{l}\text { TCKR } \\
>50 \%\end{array}$ & $\begin{array}{l}\text { Reduction of } \\
\text { PR }>50 \%\end{array}$ \\
\hline G1-2, pT1-2 & 1 & + & - \\
G3, pT3-4 & 3 & + & - \\
G1-2, pT1-2 & 3 & - & + \\
G3, pT3-4 & 2 & - & + \\
\hline Total & & & \\
\hline
\end{tabular}

TCKR, Tumor cell kill rate; PR, proliferation rate

\section{Results}

Table 2 shows the histological grade and stage of all 38 RCC tested in this study. As demonstrated, not only culturing of undifferentiated tumors but also of low-grade RCC was successful.

All the cells of each renal tumor analyzed originated from the same primary in vitro cell culture. The PR of each untreated and treated group (two wells per group) did not differ more than $4 \%$ per group. So it can be concluded that the investigated cell suspensions exhibited a standardized in vitro growth behavior.

Figure 4 exhibits the TCKR achieved by exposing the malignant cells to the various agents (mitomycin, vinblastine, interferon-alpha-2) in different concentrations corresponding to the recommended therapeutic serum concentrations in vivo. Figure 5 compares the declining PR illustrated in Fig. 4 to the PR obtained in the control groups. Administering the chemotherapeutics at the lowest titers corresponding to recommended serum concentrations in vivo, TCKR over $50 \%$ paralleling reduction of the PR were over $50 \%$ not observed. Only four $(10.5 \%)$ of the RCC cultures exhibited TCKR over $50 \%$ and only five $(13.2 \%)$ a reduction of PR over $50 \%$ (Table 3 ).

\section{Discussion}

Increasing the efficacy of an individual chemotherapeutic agent while preventing or minimizing its inherent side effects remains an unsolved enigma in the treatment of patients with advanced RCC. In 1977 Hamburger and Salmon [11] introduced an in vitro soft agar system called the human tumor cloning assay (HTCA). To a certain extent this approach proved applicable in predicting response or resistance of a given tumor in vivo with regard to chemotherapy as attested to by various clinical studies $[1,12,18,25]$. In recent reviews the overall predictive accuracy was estimated to be $50 \%-70 \%$ for in vivo sensitivity and $91 \%-96 \%$ for in vivo resistance $[12,18$, 25].

According to these data, in more than one third of the cases a tumor has to be considered insensitive to a chemotherapeutic agent though tested to be so in vitro. However, with regard to resistance a highly reliable correlation between in vitro and in vivo results (more than $90 \%$ ) can be expected.

The success rate of colony formation in vitro for RCC averages $50 \%$, as reported recently $[12,25]$. During past years in vitro cell preparation methods have been improved, applying mechanical and enzymatic techniques. The monolayer procedure according to Kovacs et al. [16] provides an in vitro success rate for RCC of nearly $90 \%$. For routine application this method proved valuable in producing slides with high cell density, and additionally preserves material and cells [23], thus allowing simultaneous assays to be performed which are particularily suitable for in vitro drug sensitivity studies as presented herein. Reliable interpretation of tumor cell cultures essentially depends on the positive identification of malignancy and the purity of the tumor cell population as well 
$[12,22]$. For the in vitro cell preparation technique presented here this was confirmed by additional cytogenetic and immunocytochemical analyses as reported earlier $[16,22]$.

Metastatic RCC is a malignancy resistant to conventional chemotherapy $[3,13,15]$. Comparing the drugs which demonstrated at least slight therapeutic efficacy mitomycin and vinblastine are considered superior according to combined in vitro/in vivo studies $[12,25]$. The in vivo response rates reported for these agents range between $10 \%-20 \%[3,13,15]$, evidencing the need for new chemo- as well as immunotherapeutic effective strategies. The latter seen promising since in RCC immunologic interactions appear to enhance therapeutic response [3]. In this context, according to preliminary studies interferon is suggested to be active due both to its indirect and direct antineoplastic effect $[3,19]$. This prompted our interest to comparatively assess the therapeutic efficacy of mitomycin C, vinblastine, and interferon by simultaneous in vitro testing. The data obtained in this study revealed that none of these substances as claimed as anticancer drugs was able to achieve a TCKR along with simultaneous reduction of the PR of more than $50 \%$ each. Administering the drugs at the lowest concentrations corresponding to the recommended therapeutic serum titers in vivo, 9 of the $38 \mathrm{RCC}(23.7 \%)$ exhibited either TCKR over $50 \%$ or a reduction of PR over $50 \%$. Transferring these results to in vivo conditions only a temporary and limited response in patients suffering from the corresponding RCC has to be expected, followed by tumor progression, considering the highly malignant cell clones resistant to any therapeutic measure. Recent studies on in vitro sensitivity testing only considered TCKR. Therefore the immunocytochemical technique for determining the PR as developed by Gerdes et al. [7] detects one more important aspect of the complex process of the development of therapeutic resistance in vitro. Among the drugs tested in this study no significant difference was found with respect to therapeutic efficacy. The partial response rate of $23.7 \%$ obtained in vitro corresponds to clinical studies in which temporary and limited remission rates were achicved with conventional chemotherapy in patients suffering from metastatic $\mathrm{RCC}$ ranging up to $25 \%[2,3,5,6,13]$. Complete remissions, the most valuable criterion for judging success or failure of treatment hardly occur; the percentage does not differ significantly from that of patients with advanced disease who only undergo nephrectomy (incidence: $0.5 \%-4 \%$ ) [21].

\section{References}

1. Albrecht M, Simon WE, Hölzel F (1985) Individual chemosensitivity of in vitro proliferation mammary and ovarian carcinoma cells in comparison to clinical results of chemotherapy. J Cancer Res Clin Oncol 109:210

2. Bergerat JP, Herbrecht R, Dufour P, Jacqmin D, Bollack C, Prevot G, Bailly G, de Garis S (1988) Combination of recombinant interferon alpha-2a and vinblastine in advanced renal cell cancer. Cancer 62:2320

3. Buzaid AC, Todd MB (1989) Therapeutic options in renal cell carcinoma. Semin Oncol 16:12
4. Cordell JL, Falini B, Erber WN, Ghosh AK, Abdulaziz Z, MacDonald S (1984) Immunoenzymatic labeling of monoclonal antibodies using immune complexe of alkaline phosphatase and monoclonal anti-alkaline phosphatase (APAAP complexes). J Histochem Cytochem 32:219

5. Davis WH (1989) Study of recombinant interferon in advanced renal cell carcinoma. J Urol 141:140

6. Fossa SD (1988) Interferon with or without vinblastine in treatment of metastatic renal cell carcinoma. Semin Surg Oncol 4:178

7. Gerdes J (1985) An immunochistological method for estimating cell growth fractions in rapid histopathological diagnosis during surgery. Int J Cancer 35:169

8. Gerdes J, Schwab U, Lemke H, Stein H (1983) Production of a mouse monoclonal antibody reactive with a human nuclear antigen associated with cell proliferation. Int J Cancer 31:13

9. Gerdes J, Lemke H, Baisch H, Wacker HH, Schwab U, Stein H (1984) Cell cycle analysis of a cell proliferation-associated human nuclear antigen defined by the monoclonal antibody $\mathrm{Ki}-$ 67. J Immunol 133:1710

10. Gutterman JU, Fine S, Quesada JR (1982) Recombinant leukocyte A interferon: pharmacokinetics, single-dose tolerance and biologic effects in cancer patients. Ann Intern Med 96:549

11. Hamburger AW, Salmon SE (1977) Primary bioassay of human stem cells. Science 197:461

12. Hanauske AR, von Hoff DD (1985) Clinical correlations with the human tumor cloning assay. Cancer Invest 3:541

13. Harris DT (1983) Hormonal therapy and chemotherapy of renal cell carcinoma. Semin Oncol 10:422

14. Hrushesky WJ, Murphy GP (1977) Current status of the therapy of advanced renal carcinoma. J Surg Oncol 9:277

15. de Kernion JB (1986) Renal tumors. In: Walsh PC, Gittes AD, Perlmutter AD, Stamey TA (eds) Campbell's urology. Saunders, Philadelphia, p 1319

16. Kovacs G, Szücs S, de Riese W, Baumgärtel H (1987) Specific chromosome aberration in human renal cell carcinoma. Int J Cancer 40:171

17. Leder LD, Richter HJ (1987) Renal and adrenal tumors. In: Loehr E, Leder LD (eds). Pathology of renal neoplasms. Springer, Berlin Heidelberg New York, p 15

18. Lieber MM (1984) Soft agar colony formation assay for in-vitro chemotherapy sensitivity testing of human renal cell carcinoma. J Urol 131:391

19. de Mulder PHM, Geboers ADH, Debruyne FMJ (1988) Recombinant interferons alfa and gamma in patients with metastatic renal cell carcinoma (RCC). Proc Am Soc Clin Oncol 7:126

20. Muss HB (1988) Interferon therapy of metastatic renal cell cancer. Sem Surg Oncol 4:199

21. Oliver RT (1987) Unexplained spontaneous regression and its relevance to the clinical behaviour of renal cell carcinoma and its response to interferon. Proc Ann Meet Am Soc Clin Oncol 6:383

22. de Riese W, Allhoff E, Pohl U, Lenis G, Liedke S, Atay Z, Jonas U, Warnaar SO (1989) Comparison of human normal renal cells and malignant renal cells (RCC) in vivo and in vitro using cytological, cytochemical and immunocytochemical methods. Invest Urol 3:8

23. de Riese W, Szücs S, Hoene E, Lenis G, Kovacs G (1987) Shortterm in-vitro sensitivity testing of human renal cell carcinoma. Invest Urol 2:81

24. Rinehart J, Young D, La Forge J (1987) Trial of interferon in patients with metastatic renal cell carcinoma: immunological and biological effects. Cancer Res 47:2481

25. Von Hoff DD (1987) In vitro predictive testing. Int J Cell Cloning 5:179

Dr. W. de Riese

Urologische Klinik

Medizinische Hochschule

Konstanty-Gutschow-Straße 8

W-3000 Hannover 61

Federal Republic of Germany 